\title{
Failures of Flexible Diaphragm Couplings of Power Take Off (PTO) Shafts of an Aircraft by Surface Discontinuity, Controlled by Stress Concentration or Stress Intensity Factor
}

\section{Mrityunjoy Hazra and Satyapal Singh}

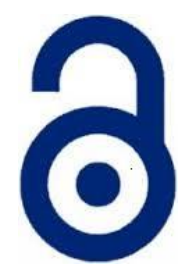

Received: 24 September 2019

Accepted: 15 June 2020

Published: 30 June 2020

Publisher: Deer Hill Publications

(c) 2020 The Author(s)

Creative Commons: CC BY 4.0

\begin{abstract}
Failures of two power take off (PTO) shafts of an aircraft have been analysed. Two shafts, one each developed by two different manufacturers failed separately during power run endurance test conducted at room temperature and ambient normal atmosphere. In both the cases, cracks were observed on the outer diaphragm disc. One shaft showed cracking in the engine side, while the other one exhibited cracks in the aircraft mounting accessory gearbox (AMAGB) side. Chemical analysis, microstructure and hardness evaluation indicate that the diaphragm material of the shafts is Ti-6Al-4V alloy used in solution treated and aged condition, as per the desired specification AMS 4928. Microstructural in-homogeneity, possibly a result of improper forging, was observed in diaphragm material of both the shafts. Additionally, surface discontinuities induced by forging and subsequent insufficient machining were noticed on the diaphragms. The diaphragms failed by fatigue with cracks possibly nucleating at surface discontinuities. Discontinuities with lower availability in one shaft led to somewhat increased life (466 million cycles) as compared to the life (104 million cycles) of the other shaft. Another possible factor contributing to lower life in the later shaft is the presence of higher quantity of nitrogen rich inclusions. Controlling factor triggering the failure of diaphragm of shaft with lower life seems to be the available high stress level along the rim periphery, while that for shaft with higher life is presence of few localized sharp surface discontinuities.
\end{abstract}

Keywords: Failure Analysis, power take off (PTO) shaft, flexible diaphragm coupling, Ti-6Al-4V, surface discontinuity, forging defects, nitrogen rich inclusion

\section{INTRODUCTION}

\subsection{Background Information}

Two power take off (PTO) shafts, one each developed by two different manufacturers separately failed during a power run endurance test carried out at room temperature and ambient normal atmosphere. A noise came out in both the cases and the tests were stopped in each case. Failure was detected in form of cracks on diaphragm discs, while inspection was carried out after the test.

\subsection{Literature Survey \\ 1.2.1 Flexible Couplings}

A coupling is a tool often used to connect two equipment such as shafts at their ends for purpose of transmitting power. There are various coupling types based on design like sleeve or muff coupling, clamp or split-muff coupling, tapered shaft lock, flexible couplings etc. [1-3]. Flexible couplings are those which are used to accommodate slight misalignment to the tune of $1.5^{\circ}$ ( $\max$ ) and some parallel misalignment. The beauty of this type which differentiates this from other varieties is its superior qualities over others, i.e. in its multipurpose use besides transferring torque [46]. These are often used to drive pumps, fans, compressors, motor generator sets, conveyers, crushers, vibrating screens etc. besides being present in critical aircraft engines. It can be major contributor to performance of two machines being connected. In this regard, construction, installation and maintenance of flexible couplings need serious attention. There are two basic functions of a flexible coupling: (i) transmitting torque between the connected driving and driven equipment, (ii) accommodating all types of misalignments, namely angular, axial (end float) and parallel

\footnotetext{
Mrityunjoy Hazra $\otimes$ and Satyapal Singh

Defence Metallurgical Research Laboratory (DMRL)

P.O. Kanchanbagh, Hyderabad 500 058, India

E-mail: mhazra@dmrl.drdo.in
}

Reference: Hazra, M. and Singh, S. (2020). Failures of Flexible Diaphragm Couplings of Power Take Off (PTO) Shafts of an Aircraft by Surface Discontinuity, Controlled by Stress Concentration or Stress Intensity Factor. International Journal of Engineering Materials and Manufacture, 5(2), 29-39. 
(offset) and any of their combinations. In addition to these functions, these couplings are also required to dampen vibration, reduce shock or peak loads, reduce noise, protect the equipment from overload or measure the output torque from the driven equipment, to accommodate thermal expansion of the equipment or any other components etc.

These couplings are often classified into following groups depending on various differentiating criteria: (i) general purpose or special purpose (high performance), (ii) lubricated or non-lubricated (dry), (iii) mechanical or metallic/elastomeric etc. A general purpose coupling falls into the special category once it is applied to very critical equipment in a system. The American Petroleum Institute (API) defines "high performance" in API 671/ISO 10441 as those with a "minimum service life of 5 years...without interruption...". Typically, there are two general categories of high performance couplings: lubricated and non-lubricated. High performance gear couplings (a mechanical element) usually require continuous oil lubrication. Metallic element types require no lubrication and are typically designed as the disc type or diaphragm type. Table 1 gives a glimpse of distinguishing traits of general and high performance couplings based on various differentiating criteria. Flexible diaphragm couplings employed in aircraft engine definitely belongs to high performance coupling types, by this definition.

\subsubsection{Working principle of a flexible diaphragm coupling connecting engine end to aircraft mounting accessory gearbox (AMAGB)}

These types of couplings transmit torque from the outside diameter (O.D.) of a flexible disc plate to the inside diameter (I.D.) across the spool, and then from I.D. to O.D. In other words, torque is transferred between I.D. section (rigid hub) and O.D. section (rigid rim) through a disc [4-11]. The disc is of variable thickness having a contoured profile approximating a hyperbola. This shape ensures uniform shear stresses and minimum bending stresses. Use of I.D. and O.D. sections of generous radii matching the disc profile reduces local stress concentration significantly and eliminates unexpected and unpredictable fatigue failures. This is also to ensure the maintenance of "infinite life" what is usually rated for a flexible diaphragm coupling by material selection and design under simultaneous actions of specified torque, speed and misalignments.

\subsubsection{Coupling Alignment and Misalignments: Their Importance}

Equipment connected by a flexible coupling should be aligned with the greatest possible accuracy. Misalignment has been found to be the major cause of coupling problems $[8,12]$. It is the deviation of relative shaft position from a collinear axis of rotation, measured at point of rotation. Misalignment occurs through bearing wear, pipe strain, base distortion due to torque, thermal changes, vibrations in the connected equipment etc. The better the initial alignment, the more capacity the system will have to accommodate any operational misalignment. Various misalignment conditions are pictorially represented in Fig. 1 [5,6,8,11,12]. No specific alignment procedure is applicable on all drives and applicable procedure is worked out individually to suit the conditions at hand. Diaphragm couplings accommodate misalignment by material flexure, and its doing so depends upon factors such as number of discs, their sizes and spacing between them.

Performance of a coupling is significantly influenced by angular as well as axial misalignments [7-11]. Both of these conditions are difficult to control in the field. Not only that, those also keep on changing with time, equipment, ambient temperature etc. Axial misalignment of a coupling is due to differential thermal expansion of the engine and mounting arrangement during operation. Occurrence as well as degree of angular misalignment has been found to be quite limited. This (angular) type along with parallel type of misalignments originates from the dynamic operating conditions in an aircraft transmission system. Free span of the flexible discs deflects to accommodate angular and minor axial misalignments. Nevertheless, angular type of misalignment has been found to be the controlling factor for diaphragm failure and it usually reaches at least three times its rated value before failure is induced. Axial and parallel misalignments distort or bend the flexible discs which are designed with thinner cross section to maintain lower bending and axial stresses for a given torque capacity. Misalignments in a coupling are often manifested by excessive vibrations. Moreover, couplings are also subjected to high cyclic stresses due to occurrence of such misalignments alone only.

\subsubsection{Coupling Failure Modes}

Failure of couplings may be due to either faults within the coupling itself (internal conditions) or external conditions $[4-7,12,13]$. Most failures due to internal faults are the result of improper or poor machining. They usually have to do with concentricities, squareness of the mating face, and tolerances on the various piloting or registering diameters. Another major cause of failure due to internal faults is improper product design. Defective materials and materials with inadequate strength and/or hardness also have contributed too many premature failures and are considered to be internal faults. On the other hand, improper installation, incorrect operation and poor maintenance are some of the external conditions influencing failure. Improper design of the flexing-element section, method of attachment to the hubs and rims, and various misalignments has been found to be the main causes of premature fatigue. Interestingly, misalignment is usually a result of both internal and external conditions, as we easily understand by this time. All couplings fail primarily because of application of the load levels beyond the capacity for which they were designed, except for rarely occurring material flaws. This is an external condition and usually comes arise out of poor maintenance and/or incorrect operation and/or incorrect installation. 
Table 1: Distinguishing traits of general and high performance couplings

\begin{tabular}{|l|l|l|}
\hline Differentiating Criteria & General Purpose Couplings & High Performance Couplings \\
\hline Design Types & Gear, Grid, Chain, Disc and Diaphragm & Gear, Disc and Diaphragm \\
\hline Material and Heat Treatment & Flame hardened AISI 1045 & Nitride hardened AISI 4140 \\
\hline Coupling Size (inch) & 1.5 to 5 & 3 to 6 \\
\hline Horsepower (HP) @ rpm (ranges) & $0.1000 @ 3000$ rpm, & $>1000$ HP @ 3600+ rpm \\
& $>1000$ HP @ 1800 rpm & \\
\hline Balancing & Non balanced & Balanced \\
\hline Configuration & Sometimes with spacers & Always with spacers \\
\hline
\end{tabular}

Table 2: Various types of coupling failures

\begin{tabular}{|c|c|c|}
\hline \multicolumn{2}{|c|}{ Cause of Coupling Failure } & Examples \\
\hline \multirow{3}{*}{$\begin{array}{l}\text { General } \\
\text { Cause }\end{array}$} & $\begin{array}{c}\text { Poor } \\
\text { Maintenance }\end{array}$ & $\begin{array}{l}\text { Failure to inspect, poor maintenance of connected equipment leading to excessive } \\
\text { loads on the couplings. }\end{array}$ \\
\hline & $\begin{array}{l}\text { Incorrect } \\
\text { Operation }\end{array}$ & Too frequent starts and stops, improper vibration monitoring, electrical faults \\
\hline & $\begin{array}{l}\text { Incorrect } \\
\text { Installation }\end{array}$ & Poor alignment, Over tight or loose fasteners \\
\hline \multirow{3}{*}{$\begin{array}{l}\text { Specific } \\
\text { Cause }\end{array}$} & $\begin{array}{c}\text { Excessive } \\
\text { Misalignment }\end{array}$ & $\begin{array}{l}\text { Poor initial alignment, unaccounted for thermal movements, foundation settling, } \\
\text { pipe strain, improper equipment mounting design or loose equipment mounting } \\
\text { bolts }\end{array}$ \\
\hline & Excessive Torque & $\begin{array}{c}\text { Electrical fault (momentary spike), unaccounted for motor induced torque } \\
\text { oscillations (synchronous motor - transient start up) }\end{array}$ \\
\hline & Other Damage & Bolt failure from too loose or too tight installation torque \\
\hline
\end{tabular}

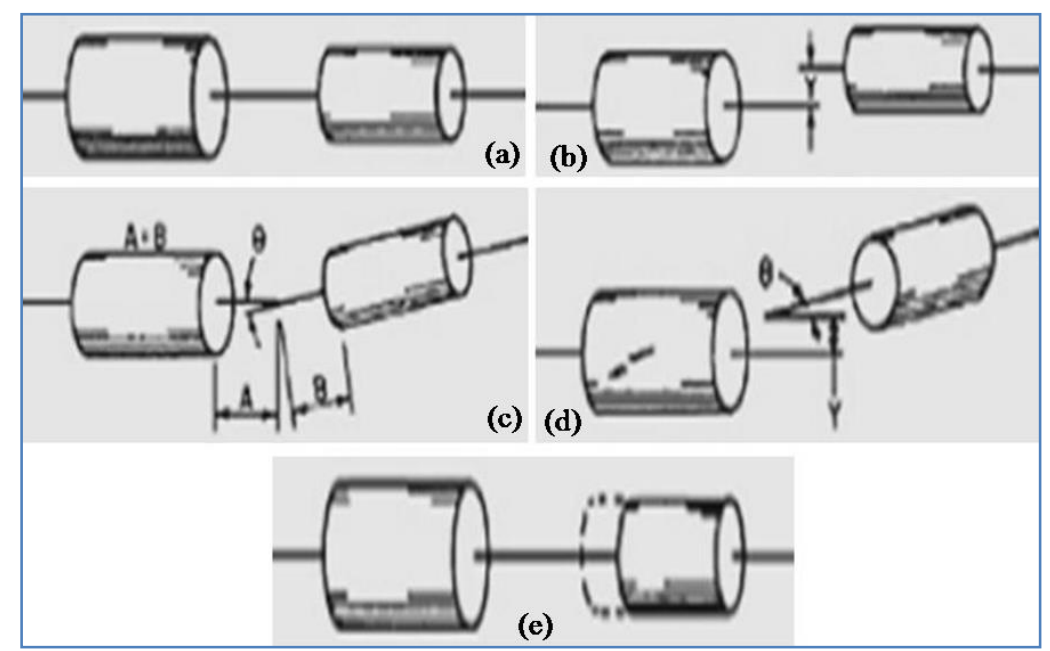

Fig. 1: Proper alignment and various misalignment types: (a) alignment, (b) parallel offset misalignment, (c) angular misalignment, (d) combined angular-offset misalignment, (e) end-float.

The over stresses so induced often lead to excessive misalignment, excessive torque (either steady state, transient, momentary spike, or oscillating) and other damaging conditions. The over stresses influence differently on different coupling to induce various reaction types and failure modes. Table 2 lists the general as well as specific causes for coupling failures and examples of each [4-7].

The most common failure modes for diaphragm couplings are due to either excess misalignment or a torque overload. Failure due to misalignment generally means excessive angular or parallel offset misalignment, with or without axial misalignment.

Angular misalignment causes an alternating stress in the web of the diaphragm as it bends back and forth with each revolution [4-7]. Failures occur due to bending fatigue and start with a crack in the flexible element. Axial misalignment often stretches the diaphragm, resulting in an additional continuous stress and contributes positively to the failure in addition to the effect of angular misalignments (Fig. 2a). On the other hand, excessive torsional oscillations can cause a fatigue crack at a $45^{\circ}$ angle to rotation (Fig. 2b). Torque overloads cause distortion of the diaphragm and can cause a rippling effect in the web (Fig. 2c). 


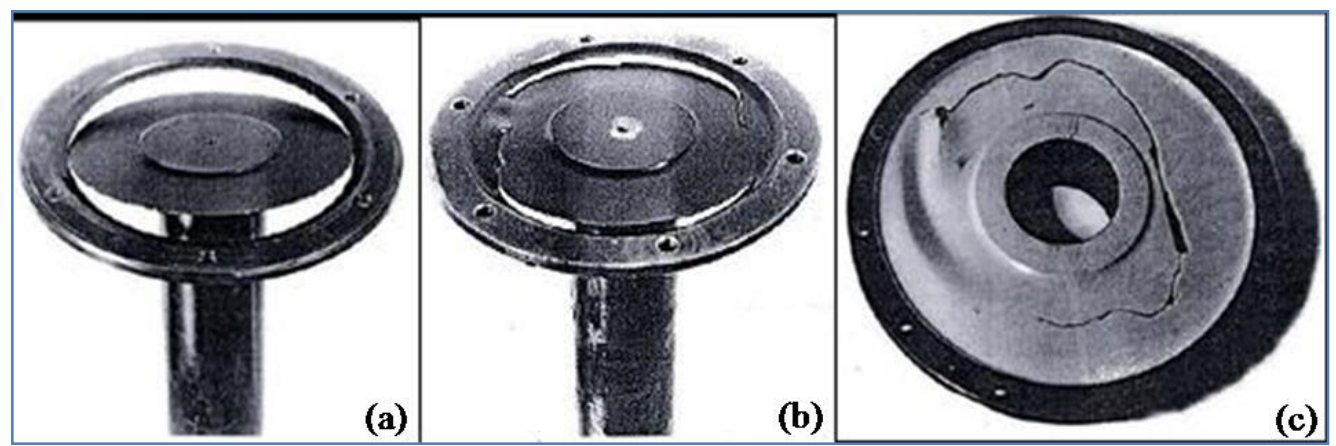

Fig. 2: Various coupling failure types: (a) under zero axial displacement, (b) under angular misalignment and large axial displacement, (c) buckling and and cracking under angular misalignment and large axial displacement.

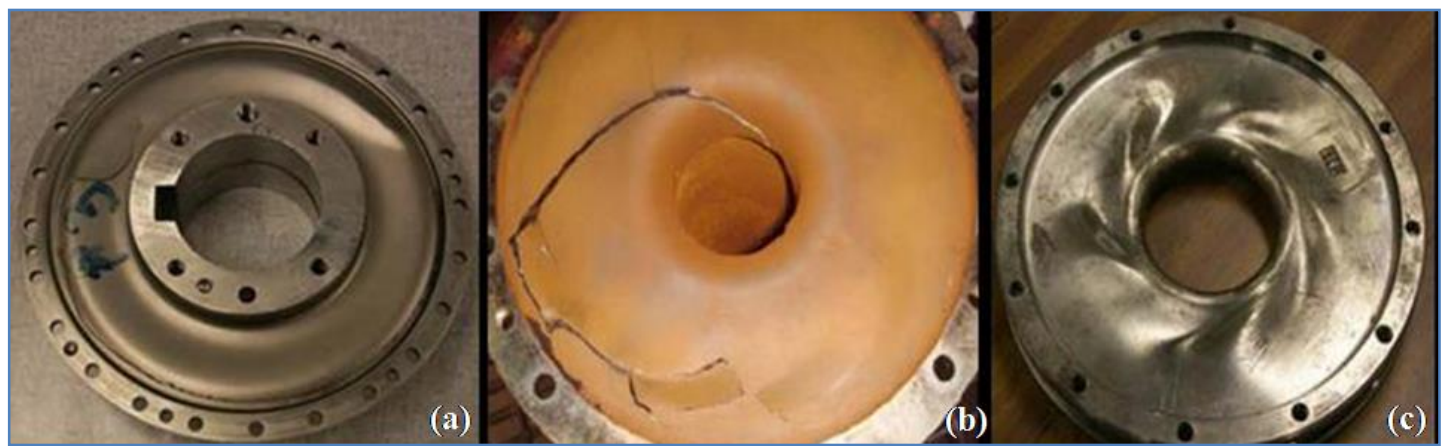

Fig. 3: Various coupling failure types - influence of stress reversal: (a) under excessive angular misalignment and axial displacement, (b) under excessive torsional oscillation, (c) under torque overload.

Magnitude of stress reversal is likely to influence the disc failure mode predominantly [13]. In case of a completely reversed stress cycles (zero mean stress), any particle on a disc is subjected to tension and compression alternately. On the other hand, for a tension-tension cycles (positive mean stress), any particle is subjected to various degrees of tension only. Likewise, two distinct failure modes are usually noticed, one at zero axial displacement and the other at large axial displacement. Fig. 3a and Fig. 3b shows diaphragm failure for case of a zero and large axial displacements respectively. Distinguishing traits of the crack path in later from that of the former are: traversing of the crack path from thinnest to the thickest portion, severe buckling of the disc in later case, and very importantly very irregular crack path in the later case. Fig. 3c shows a crack traversing $270^{\circ}$ before buckling of the disc took place, indicating that the torque load made a small contribution to the total stress on the disc.

\subsubsection{Details on the presently investigated flexible diaphragm coupling Discs}

PTO shaft of the aircraft is designed to transmit power from engine to aircraft mounting accessory gear box (AMACB). The engine is connected to the flange input of the PTO shaft, as shown in Fig. 4. Here, engine mounting accessory gear box (EMAGB), AMAGB along with PTO shaft assemblies are shown schematically. The flange output of the PTO shaft is linked to the AMAGB. It is a flexible coupling shaft rotating with constant velocity. During power transmission, misalignments (angular, axial and parallel) are encountered at the flange-shaft joints. These are absorbed by the elastic deflection/vibration of the diaphragm assembly.

A detailed drawing of the PTO shaft is shown in Fig. 4b. The shaft consists of a long tube electron beam welded to one diaphragm assembly each on both ends, EMAGB and AMAGB. There are provisions for shear bolts ( 3 nos) in the shear section in order to prevent excess torque that may be transmitted to the drives of the aircraft accessory. This is to ensure the breakage of the bolts, in case the torque exceeds a critical value. Each of the diaphragm assemblies is made of four thin circular tapered discs, each with a rim along the periphery and hub around the centre. A pair of discs consists of one thick and one thin disc. These circular discs (thick and thin) are welded along the rim. One such set comprising two welded discs is joined to another set by welding along the hub. The welding is carried out in such a way that the inner discs are thinner and the outer ones thicker. All discs are tapered from centre to periphery. The thickness of each tapered disc (thin or thick) increases from periphery (rim) to hub. The inner diaphragms have more influence on the axial stiffness and less influence on the flexural stiffness of the PTO shaft and for the outer diaphragms it is other way round. Hence, in order to maintain the flexural stiffness (flexural critical speed) and reduce the axial stiffness (axial critical speed) the inner diaphragms are made thinner than the outer diaphragms. 


\section{EXPERIMENTAL PROCEDURE}

Initially, as received failed shaft parts were examined visually by naked eye and under magnifying glass. Photographs were recorded in the as-received condition and preserved for future reference. Representative cross-sectional samples of the failed diaphragm from locations near and away from the failed region were extracted for detailed microstructural investigation using both optical and scanning electron microscopes (OM and SEM). The specimens were extracted from 4 locations namely at 12, 3, 6 and 9 O'clock positions of the intact as well as failed circular disc pairs of both engine and AMAGB side diaphragms. The specimens were examined in both unetched and etched conditions. Bulk compositional analysis of the diaphragm material was carried out by inductively coupled plasmaoptical emission spectroscopy (ICP-OES) (wet type) as well as LECO technique (dry), depending on type of elements analyzed. Compositional analyses of each phase in the microstructure were carried out by energy dispersive

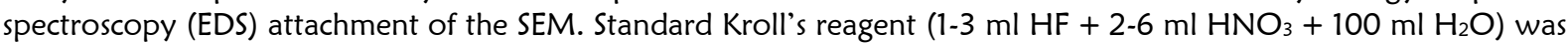
used for etching all the metallographic sections. Vickers microhardness readings at 500 gf were taken on metallographically prepared samples to correlate those with the respective microstructures.

\section{RESULTS}

\subsection{Visual examination}

Pictures of as-received PTO shafts are shown in Fig. 5. In case of shaft 1 (Fig. 5a), cracks were observed on the diaphragm disc at the engine side, i.e. close to the input end. In shaft 2 (Fig. 5b), cracks are observed on the diaphragm disc at the AMAGB side, i.e. close to the output end. Fig. $5 c$ displays position of the crack on the diaphragm discs, schematically for both the shafts. In shaft 1 , the crack covers almost $2 / 3^{\text {rd }}$ of the circumference of the rim section. In shaft 2, crack propagates almost rectilinearly in the vicinity of hub. It also covers the periphery region near the rim.

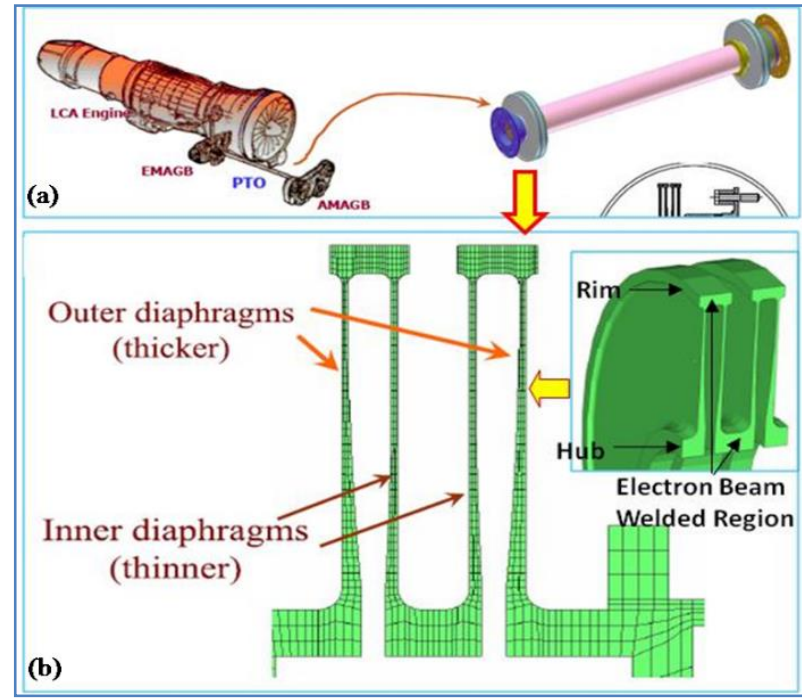

Fig. 4: (a) Schematic view of PTO shaft, EMAGB and AMAGB assemblies of aircraft system, (b) detailed schematic drawing of the flexible diaphragm couplings.

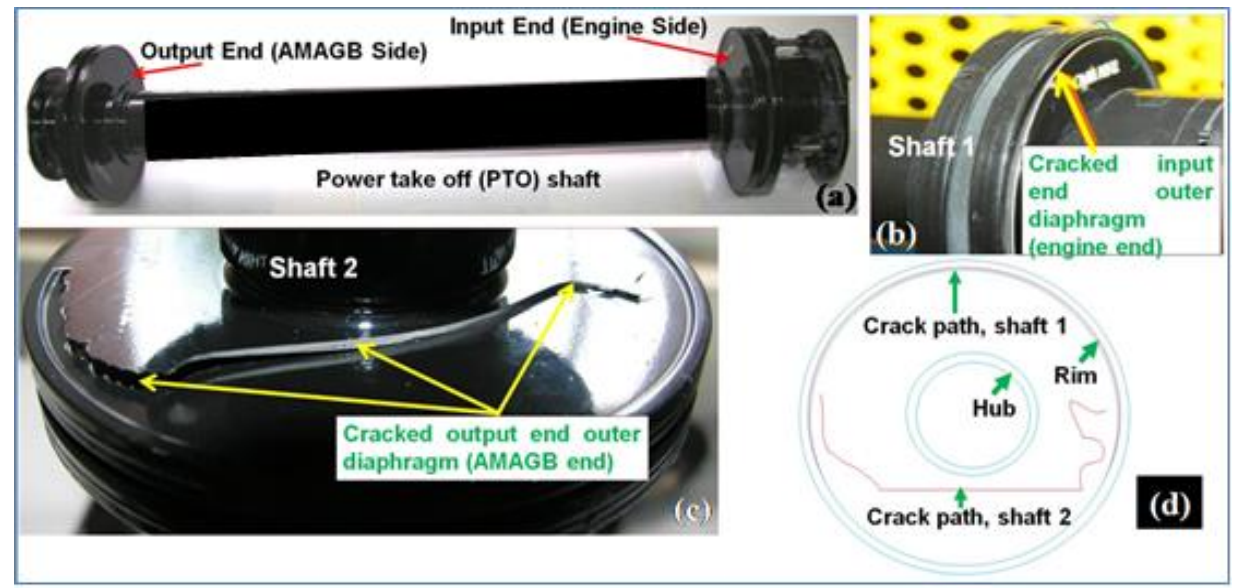

Fig. 5: As-received failed power take off (PTO) shafts - (a) general view, (b) shaft 1, (c) shaft 2, (d) schematic diagram showing the location of crack on diaphragm disc in the failed shafts. 


\subsection{Fractography \\ 3.2.1 Shaft 1}

Fractographs of the failed pieces of the diaphragm are shown in Fig. 6. Striations marked by downward arrow in Fig. $6 \mathrm{a}$ indicate that the component has failed by fatigue. The striations are also associated with micro-cracking (Fig. 6b). Fracture origin could not be identified due to severe rubbing on major portion of the fracture surfcace. Presence of particulate material, spherical and irregular shaped, was seen. The EDS results on the said features are given in Table 3. Particles 1 and 2 (Fig. 6b,c) are oxygen enriched base metal with little bit of iron. On the other hand, particle 3 reveal composition of the base metal, while 4 contains $\mathrm{Na}, \mathrm{Ca}, \mathrm{Si}$ and $\mathrm{Cl}$ in the oxygen enriched base metal. Fractographs of other local regions (Fig. 6e-g) display ductile overload failure. In this case, the particles (5 and 6) are iron and/or oxygen rich.

\subsubsection{Shaft 2}

Fractographs are shown in Fig. 7. Well defined fracture features were seen in few locations on fracture surfaces, while major parts were severely rubbed. As a result, fracture origin could not be identified. Presence of fatigue striations with multiple origins is seen in Fig. 7a,b. Overload features are shown in Fig. 7c. Particulate material (1 in Fig. 7a) containing $\mathrm{Na}, \mathrm{Ca}, \mathrm{Si}, \mathrm{Cl}$ with oxygen enriched titanium product was noticed (Table 3 ). However, the fracture surface was quite clean with respect to the presence of particulate material, unlike that was observed in case of shaft 1.
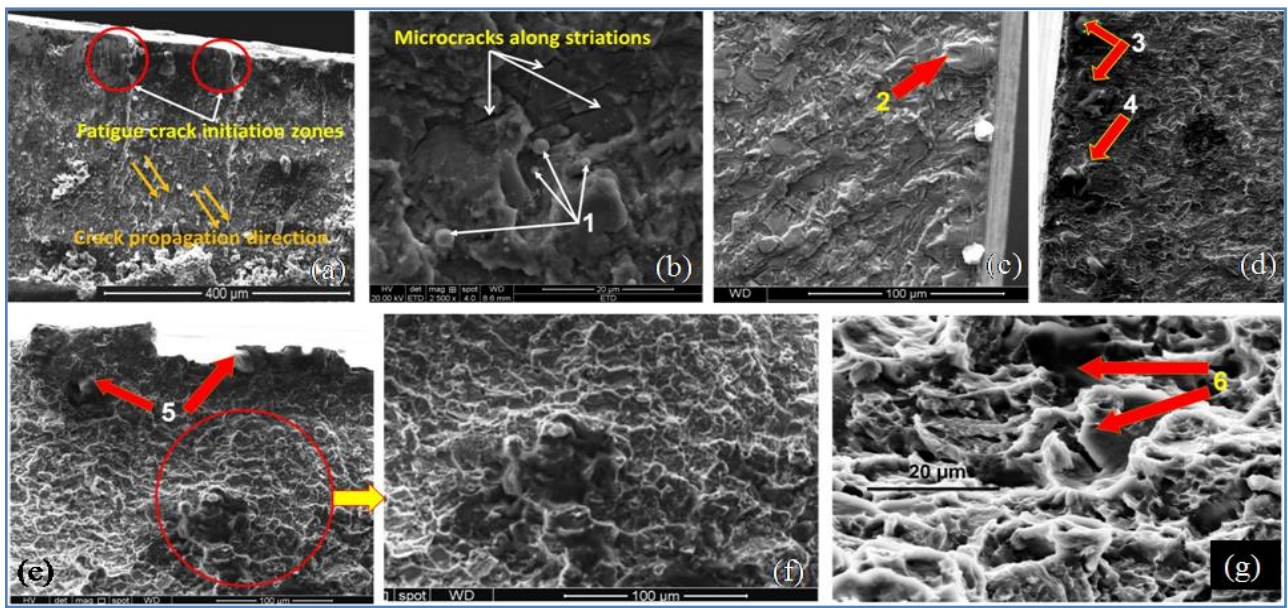

Fig. 6: Fractographs of shaft lat different locations - (a-d) fatigue fractured regions, (e-g) overload failure.
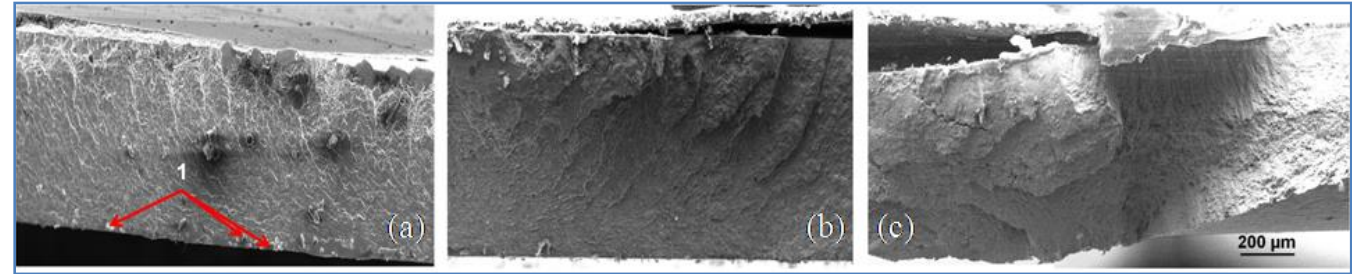

Fig. 7: Fractographs of shaft 2at different locations - (a,b) fatigue fractured regions, (c) overload failure.

\subsection{Microstructure}

Representative unetched SEM images (secondary and back scattered) of the diaphragm cross sections for both the shafts are shown in Fig. 8. This is taken from the rim region and it does represent microstructure of the other regions as well. Chain type of defects originating at surface often traversed inside as shown in Fig. 8a-c. Interior cracks of the same chain type of appearance as well as particle pull out were noticed (Fig. 8b-d). Both the surface as well as interior chain type of defects revealed composition of base metal, while EDS was carried out. Si and C have been found to be present in the region of particle pull out (point 1 in Fig. 8d, Table 3). Nitrogen rich inclusions were found in the interior of the sample (points 2 and 3 in Fig. 8e, Table 3). Surface discontinuities were observed throughout the diaphragm cross section, as is shown in Fig. 8f,h. Products rich in oxygen and titanium along with significant amount of $\mathrm{Na}, \mathrm{Ca}, \mathrm{K}$ and $\mathrm{Cl}$ were found within those discontinuities as well as at few sub-surface locations (point 4 in Fig. 8f, Table 3). Etched micrographs are shown in Fig. 8g-i. Equiaxed $\alpha$ plus transformed $\beta$ microstructure was observed throughout the base regions (away from the weld), while the weld region revealed presence of transformed $\beta$. Chain type of feature in the interior as well as on the surface with composition near to the base metal composition was well revealed after etching (Fig. 8g,h). In case of shaft 2, frequency of occurrence of both the surface discontinuities as well as nitrogen rich inclusions were quite lower as compared to those in case of shaft 1. Bulk elemental composition of the diaphragm disc material for shafts 1 and 2 are as given in Table 4 . 
Table 3: EDS analysis results on various phases as found in fractographs and microstructures

\begin{tabular}{|c|c|c|c|c|c|c|c|c|c|c|c|c|c|c|}
\hline \multirow{2}{*}{$\begin{array}{c}\text { Particle } \\
\text { No. (Fig. } \\
\text { No.) }\end{array}$} & \multicolumn{14}{|c|}{ Elements $\left(\mathrm{Wt}_{\mathrm{t}} \%\right)$, Balance $=\mathrm{Ti}$} \\
\hline & $\mathrm{C}$ & $\mathrm{O}$ & $\mathrm{N}$ & $\mathrm{Na}$ & K & $\mathrm{Ca}$ & Mo & $\mathrm{Cu}$ & $\mathrm{Ba}$ & $\mathrm{Si}$ & $\mathrm{Cl}$ & $\mathrm{Fe}$ & $\mathrm{V}$ & $\mathrm{Al}$ \\
\hline 1 (Fig. 3b) & -- & 25.3 & -- & -- & -- & -- & -- & -- & -- & -- & -- & 2.54 & 2.17 & 5.49 \\
\hline 2 (Fig. 3c) & -- & 28.6 & -- & -- & -- & -- & -- & -- & -- & -- & -- & 5.72 & 2.35 & 5.03 \\
\hline 3 (Fig. 3d) & -- & -- & -- & -- & -- & -- & -- & -- & -- & -- & -- & -- & 1.28 & 5.55 \\
\hline 4 (Fig. 3d) & -- & 28.1 & & 4.32 & & 1.87 & -- & -- & -- & 1.9 & 3.1 & -- & 2.40 & 6.80 \\
\hline 5 (Fig. 3e) & -- & & -- & -- & -- & -- & -- & -- & -- & -- & -- & 30.86 & 3.07 & 7.04 \\
\hline 6 (Fig. 3g) & -- & 26.4 & -- & -- & -- & -- & -- & -- & -- & - & & 27.31 & 1.9 & 5.77 \\
\hline 1 (Fig. 4) & -- & 24.1 & & 2.42 & & bal. & 4.63 & 5.7 & -- & 2.5 & -- & -- & 0.46 & 1.26 \\
\hline 1 (Fig. 5d) & 37.7 & -- & -- & -- & -- & -- & - & -- & -- & 42.1 & -- & -- & -- & -- \\
\hline 2 (Fig. 5e) & -- & -- & 4.5 & -- & -- & -- & -- & -- & -- & -- & -- & -- & 4.34 & 7.79 \\
\hline 3 (Fig. 5e) & -- & -- & 3.1 & -- & -- & - & -- & -- & -- & - & -- & -- & -- & 8.81 \\
\hline 4 (Fig. 5f) & -- & 37.8 & -- & 4.5 & 0.8 & 1.75 & -- & -- & -- & -- & 6.3 & -- & 0.68 & 4.20 \\
\hline
\end{tabular}

Table 4: Bulk elemental composition of diaphragm disc of shaft1 and shaft 2

\begin{tabular}{|c|c|c|c|c|c|c|}
\hline \multirow{2}{*}{ Sample ID } & \multicolumn{7}{c|}{ Content (Wt\%) } & $\mathbf{~}$ \\
\cline { 2 - 7 } & $\mathbf{O}$ & $\mathbf{N}$ & $\mathbf{H}$ & $\mathrm{V}$ & $\mathrm{Tl}$ & $\mathrm{Bal}$ \\
\hline Shaft 1 & 0.1880 & $<0.005$ & 0.0015 & 4.40 & 6.30 & $\mathrm{Bal}$ \\
\hline Shaft 2 & 0.1665 & $<0.005$ & 0.0010 & 4.20 & 6.10 & $\mathrm{~B}$ \\
\hline
\end{tabular}

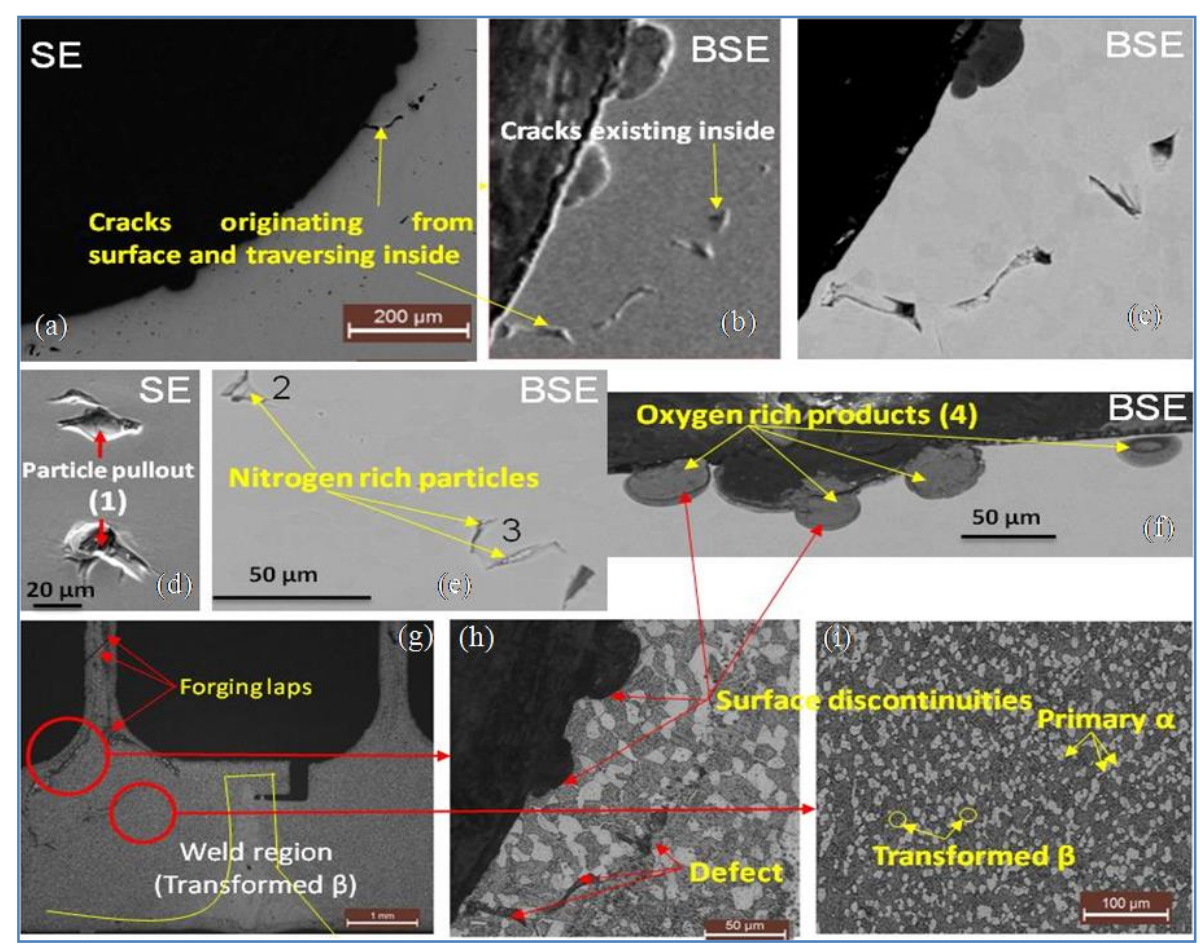

Fig. 8: Scanning electron micrographs of the rim portion of a typical outer surface cross-section of an outer diaphragm disc in SE and BSE modes - (a-f) unetched micrographs showing various defect types, (g-i) etched micrographs revealing forging laps more clearly. Etchant: Kroll's reagent.

\subsection{Hardness}

Representative hardness values were taken at different locations on transverse thick and thin sections of the diaphragm discs of the shafts. There is no difference in hardness values at different locations on the whole diaphragm cross sections. Fig. 9 is the reference figure for hardness evaluation marking typical indentation locations on both thick and thin sections of diaphragms of both the shafts. Hardness profiles along random locations like along A-A', $\mathrm{B}-\mathrm{B}^{\prime}$ and $\mathrm{C}-\mathrm{C}^{\prime}$ were also taken. Average hardness values in diaphragms in both the cases are found to be around 335 HV. 


\subsection{Stress analysis}

Probable stress patterns developing on the diaphragm discs were determined by the finite element method (FEM) of analysis. The pattern developed on the failed diaphragm discs on engine side (for shaft 1 ) and AMAGB side (for shaft 2) under the combined action of misalignments, peak operating torque and centrifugal forces are shown in Fig. 10. Maximum stress level was found to exist along some portions of the rim periphery (covering the periphery around $50 \%$ ) in both the cases. However, very low stress level is obtained in one location near the hub for the failed diaphragm of shaft 2.

It has been also found by FEM analysis that the diaphragms are so designed that the evolved stress pattern during a power run endurance test is likely to induce a mean stress of the level of $178 \mathrm{MPa}$. This leads to the lowering of the maximum allowable stress for infinite life of the diaphragm (Ti-6Al-4V) material than the usually reported value at zero mean stress level. The said limit becomes $551 \mathrm{MPa}$ instead of $420 \mathrm{MPa}$. At the same time, alternating stress was also reduced to $343 \mathrm{MPa}$ from $474 \mathrm{MPa}$ by the effect of presence of positive mean stress. In the present case, the maximum stress level and alternating stress values are $262 \mathrm{MPa}$ and $85 \mathrm{MPa}$ respectively. This indicates that the diaphragms under consideration were well designed for achieving the infinite life.

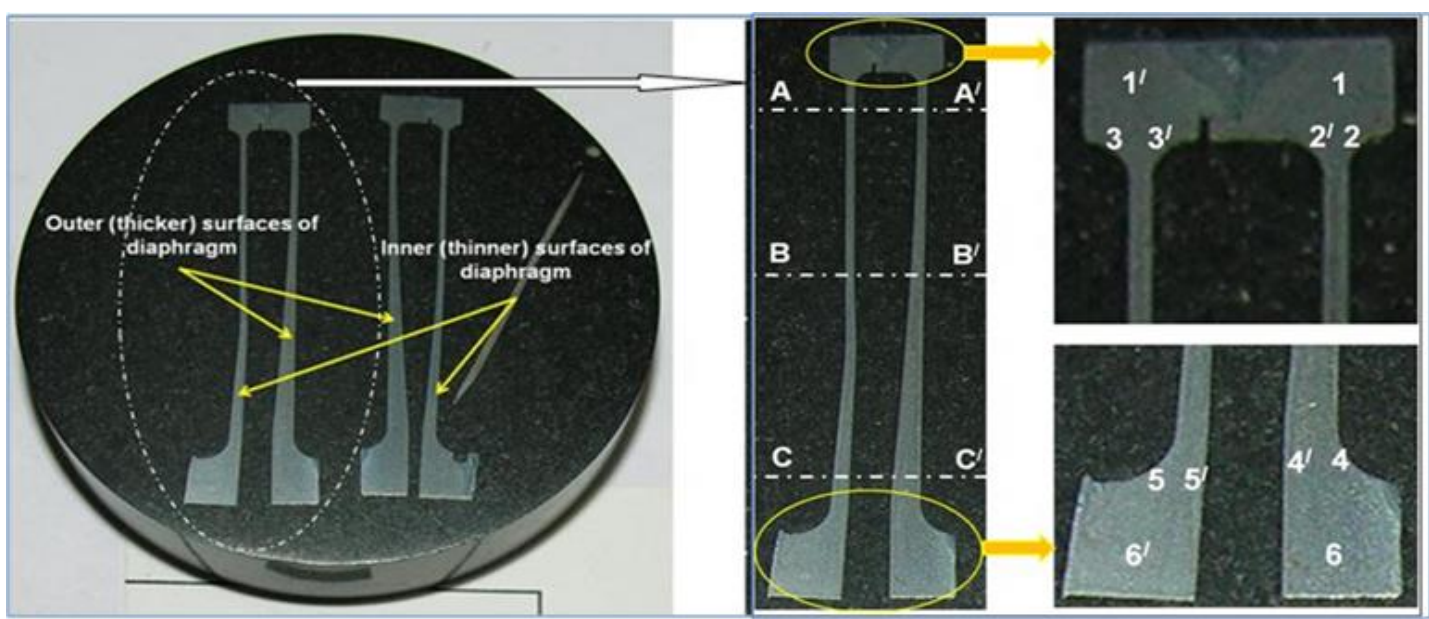

Fig. 9: Cross-sectional profile of inner and outer diaphragms of engine and AMAGB ends (marked points are for microstructure and hardness evaluation).

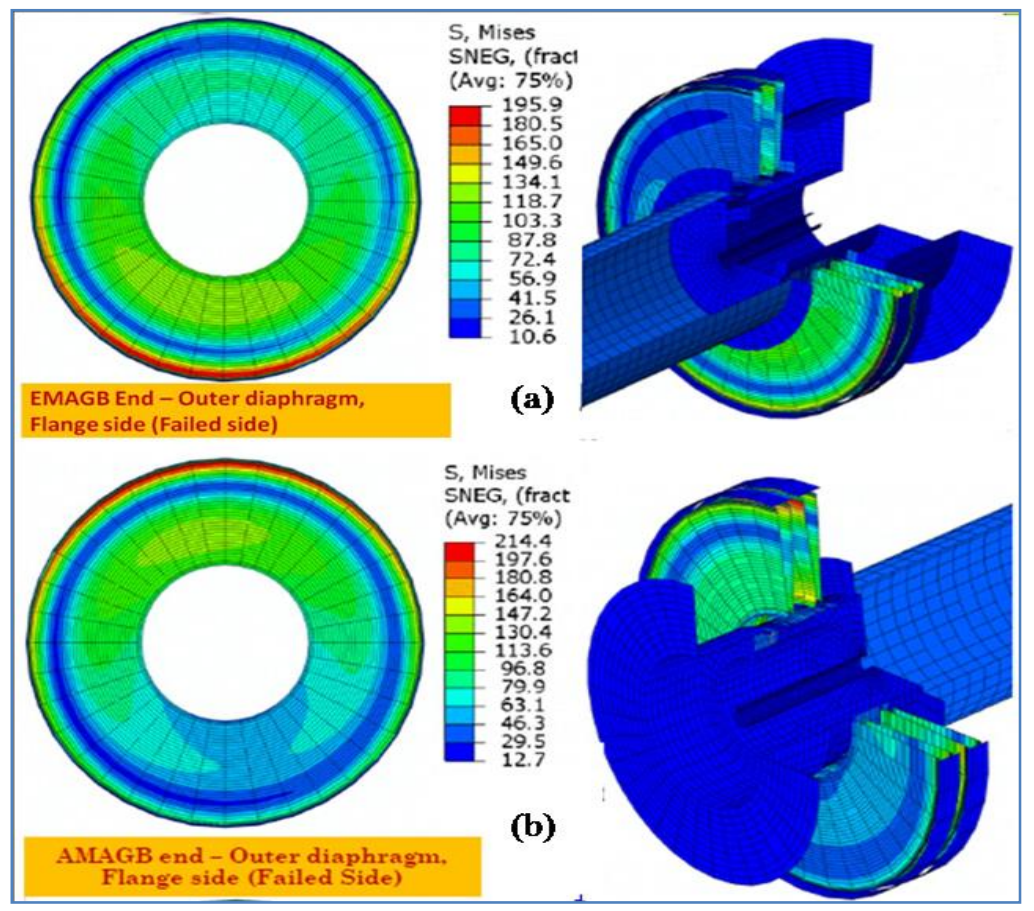

Fig. 10: Stress patterns developed on the failed diaphragms of the PTO shafts under combined actions of misalignments, peak operating torque and centrifugal forces - (a) EMAGB (engine) end outer failed diaphragms, (b) AMAGB end failed outer diaphragm. 


\section{DISCUSSION}

\subsection{Suitability of Material}

Microstructure of the diaphragm discs of both the shafts was found to be equiaxed $\alpha$ plus transformed $\beta$, as expected from solutionizing (at $955^{\circ} \mathrm{C} / 1 \mathrm{hr}$ soaking/water quench) and aging (at $540^{\circ} \mathrm{C} / 4 \mathrm{hrs}$ soaking/air cooled) heat treatment, governed by the intended AMS 4928 specification [14]. It is also supported by the chemical composition and hardness level. Forging laps or folds of same bulk (Ti-6Al-4V) composition were observed at surface as well as in the interior. Products rich in oxygen and titanium along with significant amount of $\mathrm{Na}, \mathrm{Ca}, \mathrm{K} \mathrm{Mo}, \mathrm{Si}$ and $\mathrm{Cl}$ were found within surface discontinuities as well as at few sub-surface locations (point 4 in Fig. 8f, Table 3) on the diaphragms of both the shafts. Nitrogen rich inclusions were seen in the interior portion of the diaphragm discs of both the shafts (points 2 and 3, Fig. 8e). Those inclusions cracked occasionally. The above said surface discontinuities and forging laps are most likely to be the result of high temperature forging. Particles with $\mathrm{K}, \mathrm{Ca}, \mathrm{Mo}$, Si elements sitting within those discontinuities may have originated from the glass coatings used in closed die forging of titanium alloys. Subsequent insufficient machining could not remove the mixed coating material - oxygen rich layer as well as the forging laps. Another possible origin of the defect may be the starting blanks. The characteristics of various defects present on the diaphragms of both the shafts in terms of morphology, composition and location within the disc are given in Table 5 .

Table 5: Physical characteristics of various defects on diaphragm discs

\begin{tabular}{|l|l|l|l|}
\hline Defect type & Location of occurance & Morphology & $\begin{array}{l}\text { Composition (wt\%), as } \\
\text { obtained by EDS }\end{array}$ \\
\hline $\begin{array}{l}\text { Oxygen-rich } \\
\text { inclusions }\end{array}$ & $\begin{array}{l}\text { Interior in fractographs, } \\
\text { surface and sub-surface in } \\
\text { microstructures }\end{array}$ & Circular/semi-circular shaped & $\begin{array}{l}\text { 38-40 O, 5-6 Al, 2-3 V, Ti - } \\
\text { bal. }\end{array}$ \\
\hline $\begin{array}{l}\text { Nitrogen-rich } \\
\text { inclusions }\end{array}$ & Interior - in microstructure & $\begin{array}{l}\text { Triangular, rod shaped (gelly } \\
\text { fish) type }\end{array}$ & 3-5 N, 7-8 Al, 4-5 V, Ti-bal \\
\hline \multirow{5}{*}{ Forging defects } & $\begin{array}{l}\text { Folds/laps starting from } \\
\text { surface }\end{array}$ & $\begin{array}{l}\text { Crack type, appearing dark in } \\
\text { microstructure }\end{array}$ & 3-5 O, 7-9 Al, 3-4 V, Ti-bal. \\
\cline { 2 - 4 } & $\begin{array}{l}\text { Folds/laps embedded in the } \\
\text { interior }\end{array}$ & $\begin{array}{l}\text { Crack type, appearing with } \\
\text { same contrast to that of the } \\
\text { base alloy in microstructure, } \\
\text { but with a clear boundary }\end{array}$ & Base material \\
\cline { 2 - 4 } & $\begin{array}{l}\text { Sub-surface product in 5-40 } \\
\text { mm distance below the } \\
\text { surface }\end{array}$ & Circular shaped & $\begin{array}{l}37-40 \mathrm{O}, 4-5 \mathrm{Al}, 0.50-1.00 \\
\mathrm{~K}, 4-5 \mathrm{Na}, 1-2 \mathrm{Ca}, 0.50-1.00 \\
\mathrm{~K}, \mathrm{Cl}, \mathrm{Ti}-\mathrm{bal} .\end{array}$ \\
\hline
\end{tabular}

These defects are acting as stress concentrators during testing as the torque is transferred from engine to aircraft mounting accessory gear box (AMACB) and have originated the failure. The cracks have preferentially nucleated at those regions and the propagation occurred by fatigue as seen by striations and microcracks.

Lower frequency of surface discontinuities along with the rare presence of nitrogen rich inclusions in the diaphragm material of shaft 2 might have resulted in its somewhat increased life (466 million cycles) as compared to that of the diaphragm of the shaft 1 (104 million cycles). Nevertheless, fatigue failure of the present type is most likely to have initiated from the surface discontinuities, as surface cracks are the most vulnerable locations for fatigue crack initiation.

\subsection{Influence of Mechanical Load}

Maximum stress values exist along the rim periphery of both the failed discs, as was shown in Fig. 10. This is probably due to the existence of highest stress concentration regions along the rim periphery because of the presence of thinnest diaphragm sections along with sharper (lower) fillet radius. However, failure initiation of only one diaphragm (that of the shaft 1) was along the periphery and it failed along the periphery. On the other hand, failure of the other diaphragm seems to have originated at a region between rim and hub of the diaphragm. This is supported by the (presence of a smooth linear path along major portion of the) crack profile, although origin could not be identified due to severe rubbing. Interestingly, there is a region of low stress in between rim and hub of the diaphragm disc of shaft 2, as shown in Fig. 10b. Probably, different origins of the failure of the diaphragm material of similar microstructure may be attributed to the location of attainment of the critical stress intensity factor (Kic, i.e. fracture toughness). Failure origin is that region wherein crack of considerable width and length is developed to make the failure event complete by attaining the $K_{1}$ value. Now, value of stress intensity factor $(K)$ in presence of a crack and/or discontinuity depends on both the available stress level $(\sigma)$ and notch dimension (a) by the equation:

$$
\mathrm{K}=\sigma \sqrt{ }(\pi \mathrm{a})
$$

Greater the $\mathrm{K}$ value for a notch/crack, greater is its chance to reach $K_{\mathrm{I}}$ value quickly. Now, by Eq. (1), $\mathrm{K}$ depends on the product $\sigma \sqrt{ } \mathrm{a}$, not individually on $\sigma$ and a. Thus, even if the available stress level $(\sigma)$ is quite low, for a sharper dent (i.e. bigger a), the product $\sigma \sqrt{ } \mathrm{a}$ and so $\mathrm{K}$ value may be quite high approaching to that of $\mathrm{K}_{\mathrm{l}}$. Thus, the controlling factor triggering the failure of diaphragm of shaft 1 seems to be the available high stress level along the highly stress 
concentrated rim periphery, while that for shaft 2 is presence of few localized sharp surface discontinuities. This indicates that stress concentration effect dominates the failure of shaft 1 , while the dimension of surface discontinuity and so time to reach stress intensity factor (SIF) controls the failure of shaft 2.

\subsection{Modification of defect shape}

Five things to be noted: (i) frequency of occurrence of surface discontinuity is lower in the diaphragms of shaft 2 than that of shaft 1 , (ii) the average aspect ratio $(\approx 2)$ of the surface discontinuities on diaphragms of both the shafts have been found to be the same (iii) sharpness of the surface discontinuities is the controlling factor in failure of shaft 2 unlike that for shaft 1, (iv) consumed cycles (466 million cycles) of power run endurance test is higher in case of shaft 2 than that (104 million cycles) for shaft $1,(v)$ only one surface discontinuity is likely to have taken the lead in causing the failure in both the cases. Thus, it is most likely that there was a coupling effect of shape (sharpness) of the surface discontinuities and the available stress levels on the diaphragm discs of shaft 2 . This has led to the creation of a very sharp surface discontinuity along with a low stress region in the region between rim and hub, and those happenings led to the failure under a combined effect. On the other hand, average sharpness of the discontinuities on diaphragms for both the shafts is similar, probably because of similar and homogenous microstructure in major portion of the diaphragm surfaces of both the shafts and their exposure to similar level of misalignments, peak operating torque and centrifugal forces. However, further investigation needs to be carried out on factors controlling the shape modification of surface discontinuities for both the shafts and also on coupling effect of stress distribution and defect shape modification for shaft 2 .

\section{CONCLUSIONS}

i. Surface discontinuities are most likely to have initiated failure of the diaphragm discs of both shafts.

ii. Lower frequency of occurrence of surface discontinuities in the diaphragm material of shaft 2 might have resulted in its somewhat increased life (466 million cycles) as compared to that of the diaphragm of the shaft 1 (104 million cycles).

iii. Controlling factor triggering the failure of diaphragm of shaft 1 seems to be the available high stress level along the rim periphery, while that for shaft 2 is presence of few localized sharp surface discontinuities.

iv. Surface discontinuities causing the failure are result of high temperature forging and subsequent insufficient machining.

\section{RECOMMENDATIONS}

i. Microstructural characterization of the starting blank should be carried out to detect the presence of surface irregularities, nitrogen/oxygen rich inclusions, forging lap, microstructural banding and chunky alpha. The same should be also done on the forged blanks, before final machining. All forgings as well as finished and ready to assemble discs should undergo ultrasonic flaw detection test as per AMS-2631 Class A (2mm FBH) and need to be certified by airworthiness certifying authorities [15].

ii. The starting blank for forging the Ti-6Al-4V diaphragm discs should be judiciously thicker (at least $2 \mathrm{~mm}$ thicker than that was used in present case). This is to ensure that those types of undesired defects present on and near to the surface after forging are removed completely during subsequent machining.

iii. The product should be free of any oxygen-rich layer such as alpha casing, or other surface contamination, determined by microscopic examination. In this regard, the approved and identified feed stocks may be coated with suitable temporary coatings prior to transit or during storage.

\section{ACKNOWLEDGEMENT}

The authors would like to thank Dr. Vikas Kumar, Distinguished Scientist (DS) and the Director, DMRL for his constant encouragement to work on the present field. Also, funding from DRDO is gratefully acknowledged.

\section{REFERENCES}

1. https://www.merriam-webster.com Coupling, last accessed on 18.03.2020.

2. Rivin, E. I. Criteria for Power Transmission Couplings: Part I, URL: https://sdp-si.com/Rivin/art1.php, last accessed on 18.03.2020.

3. A Review of Windsurf Universal Joint Types: http://www.unifiber.net/review-windsurf-uj-types, last accessed on 18.03.2020.

4. ANSI/AGMA 9003-B08, 2008, "Flexible Couplings - Keyless Fits", American Gear Manufacturers Association, Alexandria, Virginia, last accessed on 18.03.2020.

5. Calistrat, M. M. 1994, Flexible Couplings - Their Design Selection and Use, Houston, Texas: Caroline Publishing, last accessed on 18.03.2020.

6. "Advances in Gas Turbine Couplings", Proceedings of the Thirty-Sixth Turbomachinery Symposium, Turbomachinery Laboratory, Texas A\&M University, College Station, Texas, pp. 157-172, last accessed on 18.03.2020.

7. Rothfuss, N. B. Design and Application of Flexible Diaphragm Couplings to Industrial-Marine Gas Turbines, 73 GT-75, ASME, N.Y. 10017, last accessed on 18.03.2020. 
8. Flexible Shaft Couplings Maintenance Guide, EPRI, Palo Alto, CA: 2003. 1007910: www.epri.com, last accessed on 18.03.2020.

9. FLENDER Standard Couplings (Catalog MD 10.1 - 2009) by A. Friedrich Flender AG: www.siemens.com or www.flender.com, last accessed on 18.03.2020.

10. Features and Applications of Flexible Disc Couplings, URL: https://hvhindustrial.com/blog/Flexible-DiscCouplings-Features-Applications, last accessed on 18.03.2020.

11. Flexible Couplings, URL: http://www.tribology.co.uk/articles-papers/flexible-couplings/, last accessed on 18.03.2020.

12. Gibbons, C.B. 1976, "Coupling misalignment forces," Proceedings of the Fifth Turbo machinery Symposium Gas Turbine Laboratories \Texas A \& M University, College Station, Texas, pp. 111-116, last accessed on 18.03.2020.

13. Calistrat, M.M. Verification of Metal Diaphragm Coupling Performance in: International conference on Flexible Couplings for High Power and Speeds, June 29th, 1977, Michael Neale \& Associates Ltd., , last accessed on 18.03.2020.

14. AMS 4928: Annealed Ti-6Al-4V Alloy Bars, Wires, Forgings, Rings, and Drawn Shapes.

15. SAE AMS 2631:2017 - Ultrasonic Inspection, Titanium And Titanium Alloy Bar, Billet and Plate, https://www.sae.org/standards/content/ams2631/, last accessed on 18.03.2020. 